\title{
Myoepithelioma of Soft Palate: A Case Report and Review of Literature
}

\author{
${ }^{1}$ Arjun N Yogee, ${ }^{2}$ Raman Choudhary, ${ }^{3}$ Navneet Mathur, ${ }^{4}$ HS Bhuie
}

\begin{abstract}
Myoepitheliomas are rare benign neoplasms of salivary glands representing less than $1 \%$ of all salivary gland tumors. This tumor is usually located in the parotid gland and less frequently in the submandibular gland and minor salivary glands that are distributed throughout the oral cavity. Diagnosis of tumor is based on evaluation of histological feature, although immunohistochemical analysis confirms the myoepithelial origin of tumor cells and the final diagnosis. Herein, a case of plasmacytoid myoepithelioma of soft palate in an adult male is presented along with review of the literature.
\end{abstract}

Keywords: Myoepithelioma, Salivary gland tumors, Soft palate.

How to cite this article: Yogee AN, Choudhary R, Mathur N, Bhuie HS. Myoepithelioma of Soft Palate: A Case Report and Review of Literature. Int J Otorhinolaryngol Clin 2016;8(1):32-34.

\section{Source of support: Nil}

Conflict of interest: None

\section{INTRODUCTION}

Myoepitheliomas are rare tumors of salivary glands constituting less than $1 \%$ of all salivary gland tumors. ${ }^{1}$ It was first described by Sheldon ${ }^{2}$ in 1943, and was then considered to be a variant of pleomorphic adenoma. The most common site of myoepithelioma is parotid gland and less common locations include the submandibular gland or minor salivary glands that are distributed throughout the oral cavity. Myoepitheliomas of the soft or hard palate account for $21 \%$ of all cases and for $93 \%$ of intraoral cases. ${ }^{3}$ Myoepithelioma is composed of myoepithelial cells. Salivary glands contain myoepithelial cells, which are located between basal lamina and acinar ductal cells. Other salivary gland neoplasms that frequently contain the myoepithelial cells are pleomorphic adenoma, adenoid cystic carcinoma, and epithelial myoepithelial carcinoma of the intercalated duct origin. ${ }^{1}$ It is difficult to identify these cells in routine histological examination

\footnotetext{
${ }^{1}$ Ex-Junior Resident, ${ }^{2}$ Senior Resident, ${ }^{3}$ Assistant Professor ${ }^{4}$ Professor and Head

${ }^{1-4}$ Department of Otolaryngology Head and Neck Surgery Rabindranath Tagore Medical College, Udaipur, Rajasthan, India

Corresponding Author: Arjun N Yogee, Ex-Junior Resident Department of Otolaryngology Head and Neck Surgery Rabindranath Tagore Medical College, Udaipur, Rajasthan India, e-mail: drarjunyogee.orl@gmail.com
}

or electron microscopy and immunohistochemistry is essential to establish the diagnosis of this rare entity. 4,5 We report here a case of plasmacytoid myoepithelioma of soft palate.

\section{CASE REPORT}

A 35-year-old male presented to us with a year-old mass of soft palate, insidious in onset, progressively increasing in size, associated with change in voice, and snoring and mouth breathing during night. Mass was not associated with pain or any discharge. There was no difficulty in deglutition. Clinically, the mass was solid, firm in consistency, well-circumscribed about $4 \times 3 \mathrm{~cm}$ in size (Fig. 1). The overlying mucosa was normal and uvula was distorted. The hard palate was normal on clinical examination. No regional lymphadenopathy and other systemic problems were reported. Physical examination was normal with no sign of metastases. Radiological investigation revealed no bony abnormality (Fig. 2). Fine-needle aspiration cytology (FNAC) of the mass revealed plasmacytoid cells.

Wide surgical excision of lesion was carried out under general anesthesia. Soft palate was repaired by end-to-end suturing of mucosa. Grossly, the lesion was a well-circumscribed, gray white, solid encapsulated mass of dimension $4 \times 3.5 \times 1.5 \mathrm{~cm}$ (Fig. 3). Histologically, the tumor comprised sheets and nests of plasmacytoid myoepithelial cells with mucinous and cartilaginous differentiation. No dysplastic or malignant changes were

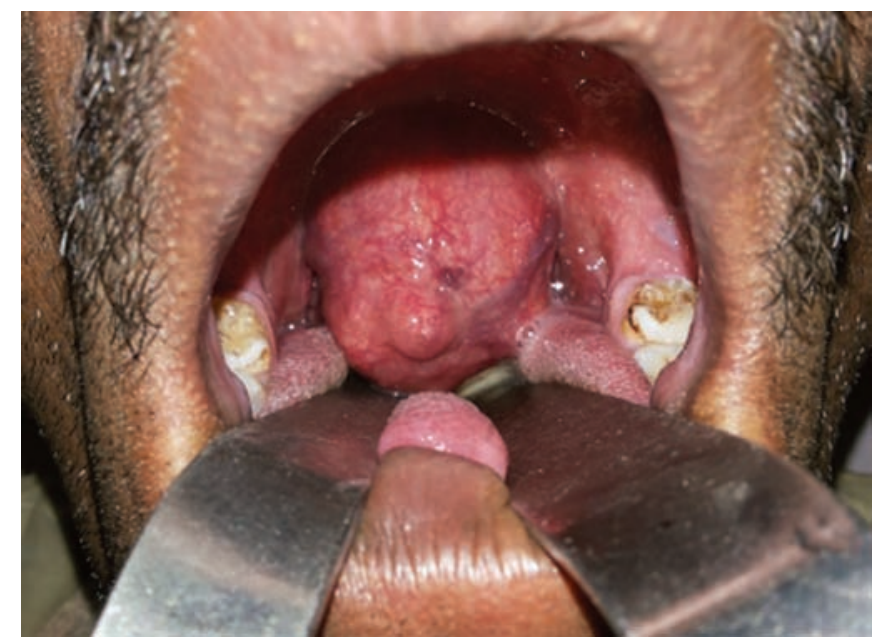

Fig.1: Intraoral view showing well-circumscribed mass of soft palate with visible submucosal blood vessels and distorted uvula 


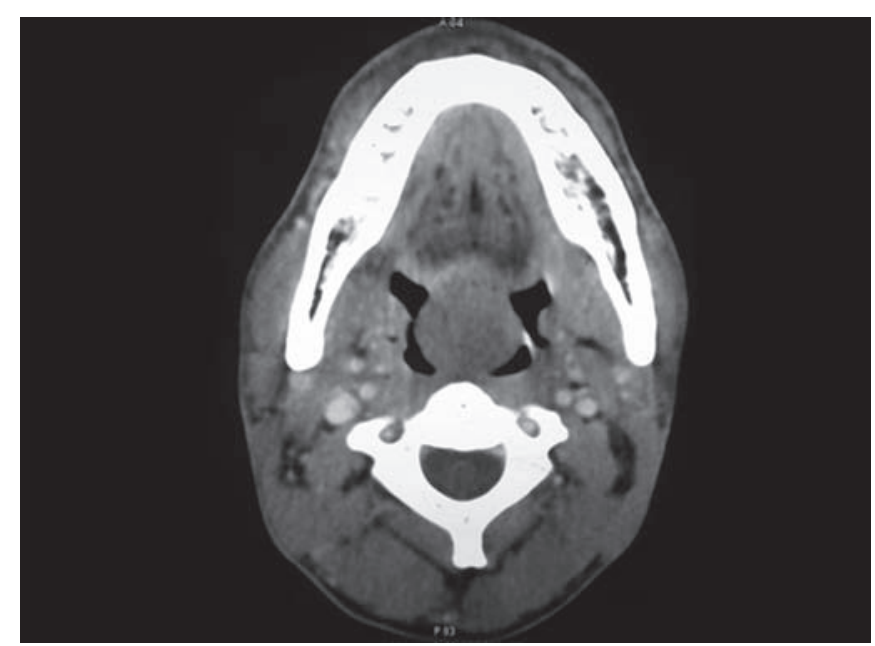

Fig. 2: Axial contrast CT image showing well-circumscribed homogenously enhancing soft tissue mass in relation to soft palate obliterating the oropharyngeal lumen

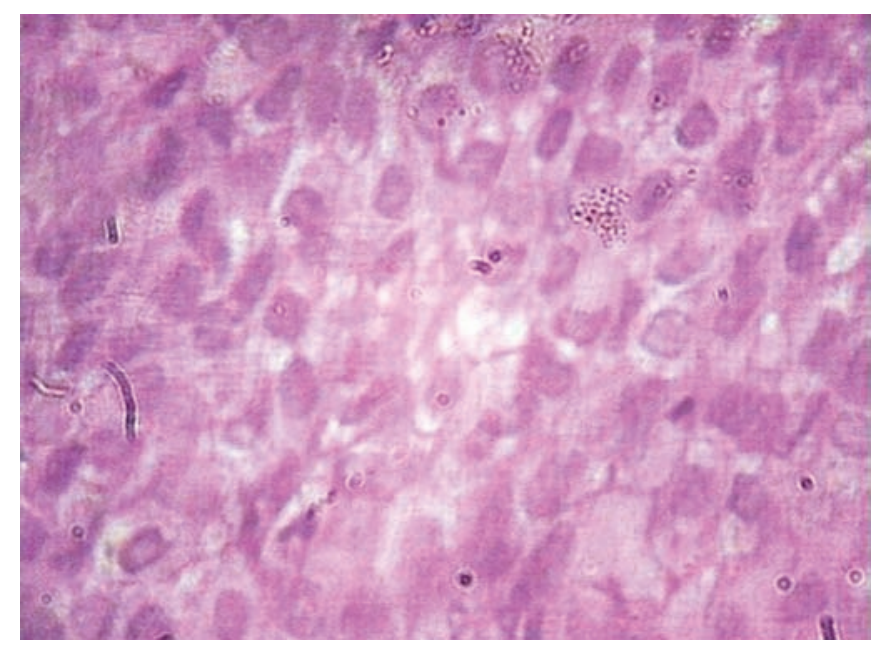

Fig. 4: Histologically tumor shows sheets and nests of plasmacytoid myoepithelial cells with mucinous and cartilaginous differentiation

observed (Fig. 4). The final histopathological examination report confirmed the diagnosis of benign plasmacytoid myoepithelioma. The patient is followed up since 2 months, with no reports of recurrence till date.

To confirm the myoepithelial nature of neoplastic cells, the immunohistochemical reaction for cytokeratin, S100, and vimentin were performed. Immunohistochemical reaction revealed positivity against all the antibodies.

\section{DISCUSSION}

Myoepitheliomas are benign neoplasms of salivary glands derived from myoepithelial cells. These tumors represent less than $1 \%$ of all salivary gland tumors. ${ }^{1}$ These tumors are commonly observed in adults aged between 30 and 50 years (average age 36.3 years). ${ }^{6}$ Myoepithelial cells are normal constituents of major and minor salivary glands and are believed to have contractile properties, which assist in the secretion of saliva. They are also found



Fig. 3: Grossly, the lesion consisted of a well-circumscribed, grey white, solid encapsulated mass with a smooth outline measuring $4 \times 3.5 \times 1.5 \mathrm{~cm}$

in breast, tracheobronchial trees, and sweat glands. These cells are found in large numbers in salivary acini and intercalated ducts, but very few cells in large excretory ducts of major glands.

The myoepithelioma may be composed of spindle cells, which are arranged in interlacing fascicles that show stroma-like appearance; ${ }^{7}$ plasmacytoid cells that are polygonal cells with eccentric nuclei; or epithelial cells arranged in nests or cords. Various architectural patterns of arrangement of these cells are nonmyxoid (solid), myxoid (pleomorphic adenoma like), reticular, and mixed. ${ }^{5}$

Although the architectural variations of myoepithelioma are well-defined, it must be emphasized that they can at times be difficult to differentiate from other tumors, particularly pleomorphic adenoma. Myoepithelioma and pleomorphic adenoma have been suggested to be two different forms of the same entity. ${ }^{8}$ It has been proposed that if the neoplasm contains less than $5 \%$ of ductal and acinar component, it must be named myoepithelioma.? It is very important to differentiate myoepithelioma from malignant neoplasms. ${ }^{9}$ Malignant tumors are differentiated from their benign counterparts by their characteristic multilobulated architecture, presence of infiltrating growth, necrotic area, polymorphism, and mitotic figures. ${ }^{10}$ Since none of these features of malignancy was observed on histopathological examination in this case, it was considered as typical benign neoplasm.

Diagnosis of tumor is based on evaluation of histological feature, although immunohistochemical analysis confirms the myoepithelial origin of tumor cells and the final diagnosis. ${ }^{11}$ Immunohistochemically, various markers have been proposed for myoepithelioma, which includes muscle-specific antigen (MSA), a marker of myogenous differentiation, and epithelial filaments of cytokeratin. ${ }^{12}$ 
S-100 protein immunoreactivity has also been used as an evidence of myoepithelial differentiation. S-100 protein is usually positive in the neoplastic myoepithelial cells but not the normal salivary gland myoepithelial cells. Vimentin (an intermediate filament protein of fibroblast and other mesenchymal cells) is one of the earliest indicators of neoplastic myoepithelial cell differentiation. ${ }^{5}$ Recently, glial fibrillary acidic protein (GFAP) is also found to be potentially expressive in myoepithelioma. Both Vimentin and GFAP are more commonly used as markers for myoepithelioma than MSA. ${ }^{4,5}$

In the case presented herein, the tumor reveals histologic features of benign plasmacytoid myoepithelioma and immunohistochemical analysis showed cytokeratin, S100 protein, and Vimentin positivity. The salivary gland tumors comprise pleomorphic adenoma, adenoid-cystic carcinoma, and epithelial-myoepithelial carcinoma. ${ }^{13}$ Although these lesions hold the myoepithelial cells as their main neoplastic cells, their clinical management may vary consistently. As adenoid-cystic carcinoma, epithelial-myoepithelial carcinoma and mucoepidermoid carcinoma demand surgical excision with postoperative intensity-modulated radiotherapy with or without chemotherapy.

On the contrary, simple surgical excision is the most accepted treatment of myoepitheliomas and other benign salivary gland tumors. Recurrence rate is very low in these tumors.

\section{CONCLUSION}

Plasmacytoid myoepitheliomas are rare salivary gland neoplasms. These should be ditinguished carefully from other tumors arising from salivary glands, such as pleomorphic adenoma and adenoid-cystic carcinoma. Along with histologic features, diagnosis should be confirmed by immunohistochemical analysis. The treatment of choice for myoepithelioma is complete surgical excision with margin of nonlesional area with very low risk of recurrence after surgery. In cases where surgical operation is not possible, radiation therapy should be considered. ${ }^{14}$

\section{ACKNOWLEDGMENT}

Authors wish to thank Dr ML Gupta for providing the histologic picture presented in this study.

\section{REFERENCES}

1. Sciubba JJ, Brannon RB. Myoepithelioma of salivary glands: report of 23 cases. Cancer $1982 \mathrm{Feb}$ 1;49(3):562-572.

2. Sheldon WH. So-called mixed tumors of the salivary glands. Arch Pathol 1943;35:1-20.

3. Ferri E, Pavon I, Armato E, Cavaleri S, Capuzzo P, Ianniello F. Myoepithelioma of a minor salivary gland of the cheek: case report. Acta Otorhinolaryngol Ital $2006 \mathrm{Feb}$;26(1):43-46.

4. Alas L, Cardesa A, Bombi JA, Mallofré C, Cuchi A, Traserra J. Myoepithelial tumors of salivary glands: a clinicopathologic, immunohistochemical, ultrastructural, and flow-cytometric study. Semin Diagn Pathol 1996 May;13(2):138-147.

5. Dardick I. Myoepithelioma: definitions and diagnostic criteria. Ultrastruct Pathol 1995 Sep-Oct;19(5):335-345.

6. Cuadra Zelaya F, Quezada Rivera D, Tapia Vazquez JL, Paez Valencia C, Gaitán Cepeda LA. Plasmacytoid myoepithelioma of the palate. Report of one case and review of the literature. Med Oral Patol Oral Cir Bucal 2007 Dec 1;12(8):E552-E555.

7. Cardesa A, Alos L. Myoepithelioma. In: Barnes L, Eveson JW, Reichart P, Sidransky D, editors. World Health Organizartion classification of tumors. Pathology and genetics of head and neck tumors. Lyon: IARC Press; 2005. p. 259-260.

8. Ellis G, Anclair P. Benign epithelial neoplasms. Tumors of salivary glands, edition 3. AFIP Atlas of Tumor Pathology, Washington DC;2002:57-68.

9. Ellis GL, Auclair PL. Benign epithelial neoplasms. In: Ellis GL, Auclair PL, editors. Tumors of the salivary glands. Silver Spring (MD): ARP Press; 2008. p. 123-133.

10. Darvishian F, Lin O. Myoepithelial cell-rich neoplasms: cytologic features of benign and malignant lesions. Cancer 2004 Dec 25;102(6):355-361.

11. Kanazawa H, Furuya T, Watanabe T, Kato J. Plasmacytoid myoepithelioma of the palate. J Oral Maxillofac Surg 1999 Jul;57(7):857-860.

12. Batsakis J, Kraemer B, Sciubba J. The pathology of head and neck tumor: the myoepithelial cell and its participation in salivary gland neoplasia, part 17. Head Neck Surg 1983 Jan-Feb;5(3):222-233.

13. Thompson SH, Bender S, Richards A. Plasmacytoid myoepithelioma of a minor salivary gland. J Oral Maxillofac Surg 1985 Apr;43(4):285-288.

14. Zormpa MT, Sarigelou AS, Eleftheriou AN, Assimaki AS, Kolokotronis AE. Plasmacytoid myoepithelioma of the palate: case report. Head Neck Pathol 2011 Jun;5(2):154-158. 